\title{
Perancangan Video Game Sebagai Media Edukasi Tentang Pandangan Kontra dari Amnesty International Terhadap Pelaksanaan Hukuman Mati
}

\author{
Liana Atmaja ${ }^{1 *}$, Denny Tri Ardianto ${ }^{2}$, Paulus Benny Setyawan ${ }^{3}$ \\ 1,2,3 Progam Studi Desain Komunikasi Visual, Fakultas Seni dan Desain, Universitas Kristen Petra, \\ Jl. Siwalankerto 121-131, Surabaya 60236, Indonesia \\ *Penulis korespondensi; Email:lianatmaja0@gmail.com
}

\begin{abstract}
Abstrak
Perubahan paradigma manusia secara kolektif di berbagai aspek kehidupan, seperti moralitas, filosofi, dan ilmu pengetahuan terjadi sebagai bagian dari perkembangan sejarah dunia, salah satunya dalam bidang hukum. Hukum yang pada mulanya bersifat retributif, di masa ini mulai mengalami pergeseran ke arah restoratif, yang mana tercermin dalam pandangan masyarakat dunia terhadap hukuman mati, di mana konsep dari hukuman mati menjadi cenderung semakin dikritisi. Indonesia mengalami ketertinggalan dalam hal itu. Dengan demikian, perancangan ini dilaksanakan sebagai respon terhadap fakta tersebut. Perancangan ini dilakukan untuk membuat media interaktif digital yang dapat menjadi media pembelajaran bagi masyarakat umum di Indonesia mengenai pandangan kontra Amnesty International terhadap isu hukuman mati. Bentuk media interaktif yang dipilih adalah Interactive Fiction, di mana materi pembelajaran dimasukkan dalam satu bentuk permainan yang bersifat naratif dan berbasis teks. Setelah dilakukan tes terhadap target audiens, hasil perancangan dinilai dapat menimbulkan ketertarikan terhadap topik yang diangkat, tetapi kurang mampu mempertahankan ketertarikan dan perhatian pemain terhadap media sebagai sebuah permainan.
\end{abstract}

Kata kunci: Hukuman mati, permainan, Amnesty International, kontra.

\begin{abstract}
A collective paradigm shift within society in various aspects of life, like morality, philosophy, and science happens as a part of the world's historical development, including in the field of law. Law which initially tends to be retributive, in today's age starts to shift towards restorative quality, which is reflected in world society's view towards the death penalty, where the concept of death penalty becomes prone to be criticized. Indonesia experiences a lag on this matter. With that in mind, this designing process is performed as a response to the situation. This designing process is performed to create a digital interactive media that can function as educational media for the general public in Indonesia concerning Amnesty International's counterview towards the death penalty issue. The form of interactive media that is chosen is Interactive Fiction, where educational materials are made part of a genre of a game that is narratively driven and textbased. After several tests towards the target audience are conducted, the result of the designing process is deemed to be able to inspire interest towards the subject matter but is ill-equipped to maintain players' interest and attention as a game.
\end{abstract}

Keywords: Death penalty, game, Amnesty International, counterview.

\section{Pendahuluan}

Perubahan paradigma manusia secara kolektif di berbagai aspek kehidupan, seperti moralitas, filosofi, dan ilmu pengetahuan terjadi sebagai bagian dari perkembangan sejarah dunia. Perubahan ini dapat teramati, contohnya pada pada akhir Perang Dunia II, dimana nilai-nilai hak asasi manusia menjadi semakin dikukuhkan dengan diadakannya penandatanganan Universal Declaration of Human Rights oleh United Nations
General Assembly. Terungkapnya berbagai tindakan-tindakan tidak manusiawi yang dilakukan oleh Nazi Jerman selama Perang Dunia II merupakan salah satu pemicu dari perubahan ini. Penandatanganan Universal Declaration of Human Rights ini mendorong diterimanya nilainilai hak asasi manusia secara luas oleh masyarakat dunia.

Penerimaan nilai-nilai hak asasi manusia oleh masyarakat dunia ini berdampak pada pergeseran 
dari tujuan pemidanaan, dimana nilai-nilai kemanusiaan dinilai tinggi dan perlakuan terhadap pelaku kejahatan dituntut untuk lebih manusiawi. Tujuan pemidanaan dapat diuraikan menjadi tujuan (1) retributif, (2) deterrence, (3) treatment, (4) social defence dan (5) restorative justice (Mulyadi, 2010:84). Tujuan-tujuan yang melandasi pemidanaan hukum Indonesia ini dikritik oleh Mulyadi (Mulyadi, 2010:88) karena dianggap terlalu kejam dan bertentangan dengan nilai- nilai kemanusiaan dan gagal mengurangi angka kriminalitas dengan fakta semakin meningkatnya jumlah pelaku yang menjadi residivis. Mudzakkir mengutarakan bahwa konsep keadilan dalam penal policy seharusnya digeser dari perspektif keadilan retributif ke perspektif keadilan restoratif (Mulyadi, 2010:88).

Dalam situasi yang demikian, hukuman mati sebagai bentuk hukuman yang bersifat retributif dan deterrent, serta secara prinsip melanggar hak asasi manusia, banyak ditolak oleh negara-negara di dunia dengan semakin banyaknya negara yang menyatakan abolisi hukuman mati dari bentuk hukuman yang dilaksanakannya. Banyak komunitas internasional yang mendukung dilakukannya abolisi hukuman mati secara menyeluruh. Amnesty International merupakan salah satu organisasi internasional yang mendukung posisi tersebut. Aktivitas organisasi ini berfokus pada advokasi melawan pelanggaran HAM, termasuk mengenai pemberlakuan hukuman mati. Dengan pengalaman dan dedikasinya terhadap gerakan abolisi pelaksanaan hukuman mati di dunia selama 40 tahun, argumen yang diajukan terhadap pelaksanaan hukuman mati dari organisasi ini patut dijadikan referensi untuk mempelajari pandangan kontra terhadap isu ini.

Sayangnya, Indonesia masih tertinggal dalam persepsinya terhadap tujuan pemidanaan, dimana pemidanaan masih dipandang sebagai ganjaran atas pelanggaran hukum (keadilan retributif), yang sebagai konsekuensinya memperkenankan hukuman mati dilaksanakan pada pelaku-pelaku tindak pidana yang dianggap pantas memperolehnya. Sebagai bukti, keputusan pelaksana hukum Indonesia untuk menjatuhkan hukuman mati terhadap para terdakwa kasus peredaran narkotika Bali Nine pada tahun 2015 lalu tidak banyak memperoleh oposisi dan kritisi oleh masyarakat Indonesia dan malah memperoleh dukungan kuat dari masyarakat (Bayuni, 2015). Menurut Lubis (Lubis, 2015:10), hal ini disebabkan oleh nilai kultural di Indonesia yang menghargai tindakan retribusi dan balas dendam. Hukuman terhadap narapidana, termasuk hukuman mati, dianggap sebagai balasan atas perbuatan mereka. Di komunitas tertentu, terdapat keyakinan bahwa hukuman mati tidak hanya berperan sebagai pencegah, tetapi dapat memulihkan ketertiban dan kehormatan (Lubis, 1993:19-21).

Di luar keadaan nilai kultural yang dominan dalam masyarakat saat ini, terdapat pula unsur nasionalisme yang berbahaya yang semakin mendukung keberadaan hukuman mati sebagai bentuk pemidanaan di Indonesia. Bayuni (2015) mengamati bahwa pelaksanaan hukuman mati oleh presiden seringkali dimuati motif politik. Untuk menjustifikasi pelaksanaan hukuman mati terhadap narapidana Bali Nine, Presiden Joko Widodo berargumen bahwa hukuman mati perlu dilaksanakan untuk menindak peredaran narkotika di dalam negeri karena Indonesia tengah menghadapi krisis obat-obatan terlarang. Dengan kata lain, pelaksanaan hukuman mati dijustifikasikan sebagai upaya untuk melindungi negara. Meski demikian, Presiden Jokowi gagal untuk mendukung pernyataan ini dengan data yang dapat dipercaya dan klaimnya telah ditantang oleh para akademisi dan aktivis (Suara Pembaruan, 2015). Namun, pemerintah berargumen pula bahwa mundur dari keputusan untuk menjatuhkan hukuman mati itu dapat merusak reputasi Indonesia di mata masyarakat internasional dan menolak untuk menunggu proses hukum sampai selesai (Lubis, 2015:12).

Tampak bahwa pemerintah dominan mengambil posisi pro dalam diskusi mengenai pelaksanaan hukuman mati ini. Masyarakat rawan terjebak dalam satu sudut pandang ini saja karena secara alami menaruh kepercayaan pada pemerintah dan kepala negara. Sudut pandang yang berbeda dan pengetahuan yang lebih mendalam akan isu pelaksanaan hukuman mati diperlukan untuk dapat melihat isu ini secara komprehensif. Dengan memahami berbagai sudut pandang mengenai isu ini, masyarakat dapat membentuk opini yang lebih terpelajar dan lebih relevan.

Perancangan ini dilaksanakan untuk membuat media yang dapat mengedukasikan argumen kontra terhadap pemberlakuan dan pelaksanaan hukuman mati kepada target audiens agar dapat mengimbangi pandangan pro yang dominan di Indonesia. Untuk itu, video game dipilih sebagai media yang dinilai sesuai dengan target audiens. Media yang demikian dipilih dengan pertimbangan bahwa media ini akan lebih mudah diakses di masa dimana internet dan teknologi digital seputarnya telah menjadi bagian tidak terpisahkan dari kehidupan sehari-hari masyarakat saat ini. Sebuah perancangan media untuk mengedukasi kan materi pendidikan kewarganegaraan yang 
ditujukan kepada murid SMA dapat digunakan sebagai referensi dalam melakukan perancangan ini, terutama karena salah satu topik yang difokuskan kepada hak asasi manusia (Hayati, Radiana, Sulistyarini, 2014). Sasaran target audiens yang dimaksud adalah individu yang tergabung dalam kelompok usia 20-30 tahun, yang mana termasuk dalam kelompok pengguna internet yang aktif (Katadata, 2018). Mereka merupakan kelompok masyarakat produktif, memiliki hak politik, dapat terlibat dalam diskusi mengenai isu sosial sekaligus tertarik terhadapnya, dan masih cukup muda untuk diasumsikan belum mengembangkan opini yang kuat mengenai isu pelaksanaan hukuman mati di Indonesia. Media video game yang akan dirancang diharapkan dapat menarik bagi individu-individu demikian yang sejak awal telah memiliki ketertarikan terhadap video game.

\section{Metode Perancangan}

\section{Data Primer}

Data primer yang dikumpulkan untuk perancangan ini antara lain adalah artikel dari situs online, jurnal, buku dan laporan yang ditulis oleh ahli-ahli mengenai hak asasi manusia, hukum, kriminologi dan bidang- bidang lain yang terkait. Data dikumpulkan dengan melakukan tinjauan pustaka dengan menggunakan internet dan mencari buku fisik di perpustakaan.

\section{Data Sekunder}

Data sekunder yang dikumpulkan untuk perancangan ini antara lain adalah teori mengenai prinsip pengembangan video game dan referensi video game yang unik berdasarkan kapabilitasnya untuk mempengaruhi pemain, yang dikumpulkan dengan menggunakan media internet di berbagai situs terkait.

\section{Instrumen/Alat Pengumpulan Data}

Pengumpulan data dilakukan dengan memanfaatkan media internet untuk mencari artikel, jurnal ilmiah yang berbentuk digital, dan buku berbentuk digital. Di luar itu, pencarian data juga dapat dilakukan dengan mencari buku fisik di perpustakaan.

\section{Metode Analisis Data}

Metode yang digunakan bersifat deskriptif kualitatif karena data yang dianalisis merupakan data non-numerik. Dengan kata lain, penelitian dilakukan terhadap sekelompok manusia, suatu objek, suatu set kondisi, suatu sistem pemikiran ataupun suatu kelas peristiwa di masa sekarang. Metode ini dipilih untuk memahami subjek dan objek perancangan dengan lebih mendalam.

Data yang hendak dianalisis merupakan berbagai informasi dari sumber ahli dan berita yang diperoleh dengan berbagai cara seperti yang disebutkan pada sub bab sebelumnya. Hasil dari pelaksanaan metode ini merupakan rangkuman informasi yang dibutuhkan bagi target audiens untuk memberikan pemahaman mengenai diskusi seputar hukuman mati dan terutama pandangan kontra Amnesty International terhadapnya. Demikian, disimpulkan bahwa metode analisis data kualitatif merupakan metode yang paling cocok untuk merancang video game untuk mengedukasikan pandangan kontra Amnesty International terhadap pemberlakuan hukuman mati.

\section{Pembahasan}

\section{Hukuman Mati}

Hood (2019) mendefinisikan hukuman mati (capital punishment) sebagai "execution of an offender sentenced to death after conviction by a court of law of a criminal offense" [eksekusi dari pelanggar yang dijatuhi hukuman mati setelah dakwaan dari pengadilan hukum atas pelanggaran kriminal]. Istilah death penalty terkadang digunakan menggantikan istilah capital punishment, tetapi secara fundamental memiliki perbedaan dimana kata 'penalty'dalam death penalty mengimplikasikan kemungkinan bahwa pembebanan hukuman tidak selalu berakhir pada eksekusi, melainkan memiliki kemungkinan terjadinya perubahan pemidanaan menjadi hokuman kurungan seumur hidup.

Angka pelaksanaan hukuman mati di banyak bagian di dunia mengalami penurunan yang signifikan sejak pertengahan abad lalu. Per tahun 1970, hanya ada 21 negara yang mengabolisi hukuman mati dari segala bentuk tindakan kriminal atau terhadap "ordinary offense" [pelanggaran biasa], yang mana meliputi semua bentuk pelanggaran hukum selain pemberontakan terhadap pemerintah dan pelanggaran pada masa perang. Sementara, terdapat 58 negara yang masih memberlakukan hukuman mati dan tetap terus melaksanakan eksekusi (Johnson, 2010). Namun, per Juli tahun 2018 terdapat 106 negara yang menyatakan mengabolisi hukuman mati dari segala bentuk kejahatan (abolitionist for all crimes), 8 negara mengabolisi hanya untuk bentuk kejahatan biasa (abolitionist for ordinary crimes), dengan 28 negara tidak secara resmi menyatakan 
abolisi tetapi tidak melaksanakan eksekusi selama 10 tahun terakhir (abolitionist in practice). Sebagai perbandingan, negara dan teritori yang masih memberlakukan hukuman mati untuk kejahatan biasa (retentionist) per tahun 2018 ada sejumlah 56 negara (Amnesty International, 2018). Indonesia termasuk dalam daftar 56 negara retentionist ini.

Meski tren internasional saat ini cenderung mengarah ke abolisi, terdapat empat wilayah di dunia yang mayoritas negara-negara di wilayah tersebut masih mempertahankan hukuman mati dalam sistem hukumnya. Salah satu dari empat wilayah itu adalah Amerika Serikat, yang mana masih mempertahankan hukuman mati dalam sistem federalnya dan di 35 negara bagian, dengan pelaksanaan eksekusi sebagian besar terjadi di beberapa negara bagian di wilayah selatan. Di Karibia, 11 dari 13 negara mempertahankan hukuman mati tetapi jarang melaksanakan eksekusi. Timur Tengah dengan negara-negara yang mayoritas merupakan negara Islam termasuk dalam keempat wilayah yang dimaksud. Namun, Asia yang menghimpun setidaknya $60 \%$ dari populasi dunia merupakan wilayah dimana $90 \%$ dari angka pelaksanaan eksekusi di seluruh dunia terkonsentrasi, dengan jumlah yang signifikan berasal dari Cina.

\section{Amnesty International}

Amnesty International merupakan sebuah organisasi internasional non-pemerintah yang melakukan advokasi terhadap pembelaan hak asasi manusia, termasuk dalam gerakan abolisi hokuman mati di seluruh dunia. Amnesty International didirikan oleh Peter Benenson, seorang pengacara Inggris Raya pada Juli 1961 bersama seorang profesor hukum dan kawannya, Philip James. Keanggotaan Amnesty International tersebar di berbagai negara di dunia, dimana sebagian besar anggotanya merupakan sukarelawan, sementara terdapat pula sejumlah kecil tenaga kerja profesional yang digaji di dalam keanggotaannya.

Amnesty International memiliki enam isu terkait hak asasi manusia yang dijadikan fokus dalam aktivitasnya: hak wanita, anak, dan kaum pribumi, penghentian praktik penyiksaan, abolisi hukuman mati, hak pengungsi, hak dari "prisoner of conscience" (istilah yang diciptakan dan didefinisikan oleh Peter Benenson pada tahun 1961 yang merujuk pada orang-orang yang dipenjara karena ras, orientasi seksual, agama, atau pandangan politik tertentu, termasuk orang-orang yang menerima perlakuan buruk karena mengekspresikan pandangan dan kepercayaan mereka secara damai).
Diambil dari situs resminya (2019), argumen yang diajukan oleh Amnesty International untuk mendukung abolisi pelaksanaan hukuman mati antara lain; 1) it is irreversible and mistakes happen [hukuman mati tidak dapat ditarik kembali, sementara kesalahan selalu mungkin terjadi], 2) it does not deter crime [hukuman mati tidak mengurangi kriminalitas], 3) it is often used within skewed justice system [hukuman mati seringkali dilaksanakan dalam sistem peradilan yang cacat], 4) it is discriminatory [hukuman mati bersifat diskriminatif], dan 5) it is used as a political tool [hukuman mati seringkali digunakan sebagai alat politik].

Poin pertama mengungkapkan bahwa keputusan penjatuhan hukuman mati kepada seseorang tidak dapat ditarik kembali dan pada kenyataannya kesalahan selalu mungkin dan memang terjadi. Kemungkinan bahwa kesalahan dapat terjadi dalam pelaksanaan sistem hukum di berbagai bagiannya tidak dapat disangkal, baik itu disengaja atau tidak. Kesalahan manusia, keterbatasan bukti, saksi, dan teknologi forensik yang ada mungkin dapat menyebabkan kesalahan tersebut.

Poin kedua mengungkapkan bahwa pelaksanaan hukuman mati tidak mengurangi angka kriminalitas. Salah satu argumen pendukung pelaksanaan hukuman mati adalah klaim bahwa pelaksanaan hukuman mati dapat mendorong individu-individu yang beresiko melakukan tindakan kriminal untuk tidak melakukannya, sehingga dampaknya diharapkan dapat mengurangi angka kriminalitas. Namun, bukti terhadap klaim ini tidaklah konsisten dari setiap kasus yang ada. Faktanya, di Indonesia sendiri, menurut Todung Mulya Lubis (2015, p.20), "crime rates have not declined despite the fact that executions have taken place regularly" [angka kriminalitas tidak berkurang meski eksekusi telah dilaksanakan secara reguler]. Pelaksanaan hukuman mati di Indonesia tidak berkurang sejak transisi demokrasi pada tahun 1998, dan malah semakin banyak dilakukan sejak demokrasi diperkenalkan di Indonesia (McRae, 2012, p.5).

Poin ketiga, keempat dan kelima yang telah disebutkan sebelumnya pada prinsipnya disebabkan oleh keberadaan sistem peradilan dalam masyarakat yang memiliki bias dan prasangka terhadap kelompok masyarakat tertentu, dijalankan oleh agen-agen yang korup, atau dipengaruhi oleh pihak-pihak dengan motif politik tertentu. Dengan kata lain, sistem hukum yang ada tidak dapat beroperasi secara ideal dengan sempurna dan dapat mengadili dengan benar-benar adil. Dalam keadaan yang demikian, seperti halnya 
yang diungkapkan di poin pertama, adanya penjatuhan hukuman mati yang salah diberikan merupakan kemungkinan yang nyata dan selalu dapat terjadi.

\section{Media Pembelajaran Interaktif}

Katsaounidou, Vrysis, Kotsakis, Dimoulas, \& Veglis (2019) mengaitkan proses pembelajaran dengan bentuk media interaktif berupa permainan (game). Ia menggunakan istilah gamification approach (pendekatan gamifikasi) dalam konteks tersebut, yang mana disebut sebagai " $a$ useful tool for informal training, taking advantage of the appealing storytelling, their engaging character, the power of the visual media, and overall, the dynamics of the technological capacities and the rich media experience" [alat yang berguna untuk pelatihan non formal, memanfaatkan alur penyampaian cerita dan tokoh yang menarik, kekuatan dari media visual dan secara keseluruhan, dinamika dari kapabilitas teknologi dan pengalaman media yang kaya]. Istilah gamifikasi itu sendiri didefinisikan oleh Deterding, Dixon, Khaled, \& Nacke (2011) dalam konteks akademis sebagai "the use of game design elements in nongame contexts." [penggunaan elemen desain permainan dalam konteks di luar permainan].

Melanjutkan apa yang diungkapkan oleh Katsaounidou, Vrysis, Kotsakis,, Dimoulas, \& Veglis, mereka mengatakan bahwa "gamification has become a favorite subject for academic research and development, since it is considered a promising future educational approach" [gamifikasi telah menjadi subjek favorit dalam penelitian dan pengembangan akademis, karena ia dianggap sebagai pendekatan edukatif baru yang menjanjikan], melihat hasil studi dalam konteks edukasi mengenai hasil dari proses pembelajaran yang mengalami gamifikasi secara keseluruhan bersifat positif. Peserta belajar mengalami kenaikan dalam motivasi dan ketertarikan terhadap tugas yang terkait, sementara di saat bersamaan juga merasa terhibur. Meski tujuan utama dari permainan pada umumnya adalah untuk menimbulkan perasaan senang, aspek infotainment yang ada dalam permainan dan fakta bahwa hal itu dapat diaplikasikan secara luas memungkinkan bagi konsep gamifikasi ini untuk memenuhi fungsi- fungsi yang berbeda dalam berbagai aspek kehidupan seharihari, seperti dalam hal penyaluran pengetahuan. Dari sana, muncullah apa yang disebut sebagai serious game, dimana aktivitas dalam permainan didesain untuk mendorong tindakan yang diinginkan untuk dilakukan (seperti untuk keperluan pelatihan), membawakan cara yang menyenangkan untuk menyelesaikan permasalahan yang nyata. Kedua hal ini, pendekatan gamifikasi dan serious game, saling berkaitan dalam hal usaha untuk mempengaruhi aspek-aspek permainan untuk mencapai tujuan di luar fungsi permainan sebagai hiburan.

\section{Interactive Fiction}

Interactive fiction (IF) dideskripsikan oleh Montfort (2005) sebagai "work of fiction which explicitly call upon the reader to interact with them by means of queries or replies" [karya fiksi yang secara eksplisit meminta pembacanya untuk berinteraksi dengannya dengan cara berupa pertanyaan atau jawaban]. Montfort (2004) juga mendeskripsikannya sebagai "text-based genre... a program that simulates a world, understands natural language from an interactor, and provides a textual reply based on events in this world" [aliran berdasarkan pada teks... program yang mensimulasikan dunia, memahami bahasa natural dari penginteraksi, dan menyediakan jawaban berupa teks berdasarkan pada kejadian di dalam dunia tersebut]. Artinya, interactive fiction merupakan jenis media interaktif berbasis teks yang dapat menyajikan simulasi sebuah dunia pada pemainnya, dapat berkomunikasi dengan pemain dengan bahasa orang awam, dan memberi respon berupa teks terhadap peristiwa yang terjadi dalam dunia simulasi tersebut yang disebabkan oleh masukan pemain. Ryan (2009) mengkategorikan interactive fiction sebagai salah satu bentuk interactive narrative, dimana kolaborasi antara mesin dengan pengguna, atau manipulasi dari mesin data yang diproduksi oleh manusia sebagai respon terhadap masukan dari pengguna, terjadi. Pada masa ini, interactive fiction lebih banyak dikenal dengan istilah text adventure atau text game.

Interactive fiction telah ada cukup lama dalam dunia literatur. Faktanya, literatur yang diterima secara luas sebagai interactive fiction pertama, "Adventure", yang ditulis oleh Will Crowther, dirilis pada tahun 1977. Genre literatur ini telah populer memasuki tahun 1980an. Secara teknis, beberapa literatur yang dibuat dalam bentuk fisik buku atau kertas dapat disebut sebagai interactive fiction karena dapat memberi pembacanya pilihan dan jalan cerita alternatif sebagai konsekuensi dari pilihan tersebut, tetapi paling banyak dikenal dalam bentuk digital. Interactive fiction pertama "Adventure" pun dibuat dalam bentuk tersebut.

Lancy dan Hayes (1988) mengungkapkan bahwa interactive fiction dapat memungkinkan pembacanya untuk menemukan motivasi dan ketertarikan untuk menggunakan kapabilitas mereka dalam membaca untuk memenuhi kepuasan pribadi mereka. Dalam studi yang mereka lakukan, mereka menemukan bahwa orang-orang dengan 
ketertarikan rendah terhadap kegiatan membaca ternyata menunjukkan ketertarikan tinggi terhadap interactive fiction, yang mana memiliki unsur-unsur game-like di dalamnya.

\section{Konsep Kreatif}

\section{Tujuan Kreatif Pembelajaran}

Tujuan dari perancangan ini adalah untuk membuat media pembelajaran interaktif berbentuk video game dengan genre interactive fiction yang berfungsi untuk mengedukasi kelompok masyarakat yang menjadi target audiens mengenai diskusi seputar hukuman mati secara menyeluruh, dan terutama di Indonesia, dan membantu mereka mengembangkan opini yang didasarkan pada pengetahuan yang lebih luas dan lengkap mengenai topik yang bersangkutan, terutama untuk mengimbangi opini pro hukuman mati yang populer di Indonesia dengan. Media pembelajaran hendak dibuat sebagai media interaktif dengan aspek- aspek game untuk menyesuaikan proses pembelajaran dengan cara target audiens berinteraksi dengan media dan informasi.

\section{Strategi Kreatif Pembelajaran}

\section{Topik dan Tema Pembelajaran}

Tema dari materi pembelajaran media interaktif ini adalah mengenai diskusi isu seputar hukuman mati, dengan topik yang akan dibahas berkaitan dengan kasus peredaran narkoba sebagai salah satu jenis kasus yang paling mendapat perhatian, baik secara regional maupun internasional. Spesifiknya, hal-hal seperti prosedur teknis yang berkaitan dengan penjatuhan vonis hukuman mati dan beberapa undang-undang terkait, sejarah mengenai hukuman mati, poin-poin argumen dari pihak pro dan kontra hukuman mati, serta faktafakta yang memperkuat dan melemahkan argumen-argumen tersebut hendak dimasukkan ke dalam materi media.

\section{Karakteristik Target Audience}

1) Geografis

Daerah dengan penggunaan teknologi yang sudah cukup luas, seperti di sebagian besar daerah di Pulau Jawa.

2) Demografis

Usia: 20-30 tahun

Jenis kelamin: Laki-laki dan perempuan

Pekerjaan: Beragam, akademisi, masyarakat umum

Pendidikan: SMA, pendidikan tingkat lanjutan Kelas sosial: B-A atau menengah ke atas
3) Psikografis

- Tertarik atau memiliki kesadaran terhadap isu sosial dan politik

- Berwawasan atau terpelajar

- Tertarik pada video game atau game secara umum, terutama yang berfokus pada storyline

- Suka membentuk pendapat pribadi mengenai isu yang ada

- Tidak memiliki ketertarikan untuk membaca bacaan seperti buku non fiksi, koran, atau jurnal akademis

4) Behaviour

- Biasa memanfaatkan gawai dalam kehidupan sehari-hari

- Biasa mengakses berbagai konten daring

- Mengikuti perkembangan isu-isu sosial dan politik

- Memiliki aktivitas yang padat

\section{Metode Pembelajaran dan Penyajian Konten}

Metode pembelajaran dari media ini melibatkan tulisan yang berkaitan dengan narasi dan informasi sebagai elemen yang dominan, dimana pemain memperoleh pengetahuan darinya. llustrasi dan elemen audio seperti sound effect dan musik ada dalam media sebagai elemen pendukung. Bahasa yang digunakan adalah bahasa Indonesia yang cenderung formal, meski bahasa di luar itu akan digunakan jika diperlukan. Konten dalam media berfokus pada berbagai informasi terkait diskusi isu hukuman mati untuk memungkinkan target audiens untuk memahami isu tersebut secara menyeluruh. Selain itu, beberapa informasi yang bersifat sekunder yang berkaitan dengan isu hukuman mati juga dimasukkan sebagai konten. Sebagai media yang bersifat narrative-driven, sebuah jalan cerita dijadikan sarana untuk membawa informasi-informasi yang bersangkutan dan menjadi sarana pemain untuk pergi dari awal menuju akhir permainan.

\section{Program Kreatif Desain Media Pembelajaran Konsep Pembelajaran}

Konsep pembelajaran dari media yang hendak dirancang adalah pembelajaran dengan media interaktif interactive fiction yang bersifat game-like untuk mempermudah dan memotivasi pemain untuk menggunakan media agar informasi yang ada dapat tersampaikan dengan baik. Informasi disampaikan dalam bentuk bacaan yang berkaitan dengan setting narasi, dimana pemain dimaksudkan untuk memperoleh pengetahuan selagi informasi disampaikan melalui pengalaman bermain yang immersive. 


\section{Konsep Media Interaktif}

Media interaktif dibuat berdasarkan pada format interactive fiction dengan pilihan-pilihan tertentu mempengaruhi bagaimana narasi akan berjalan. Teks disertai dengan ilustrasi yang sesuai dengan adegan yang ada. Teks merupakan bagian utama dari media karena sebagian besar konten adalah berupa informasi dalam jumlah besar yang dirasa paling efektif disampaikan melalui teks, yang dikemas dalam narasi dan kombinasi antara ilustrasi dan suara.

\section{Sinopsis}

Pemain dinyatakan bersalah atas suatu tindak pidana dan dijatuhi hukuman mati. Pemain dideskripsikan berada dalam sebuah sel penjara. Pemain memilih bentuk tindak pidana yang mungkin dilakukannya sehingga dapat membuatnya memperoleh vonis hukuman mati, atau menolak sama sekali vonis itu.

\section{Konsep Visual}

Color tone yang akan digunakan adalah warnawarna pastel dengan undertone dominan warna merah- kuning. Tujuan dari pemilihan warna yang demikian adalah untuk menimbulkan kesan melankolis dengan penggabungan warna-warna hangat yang diselingi warna dingin.
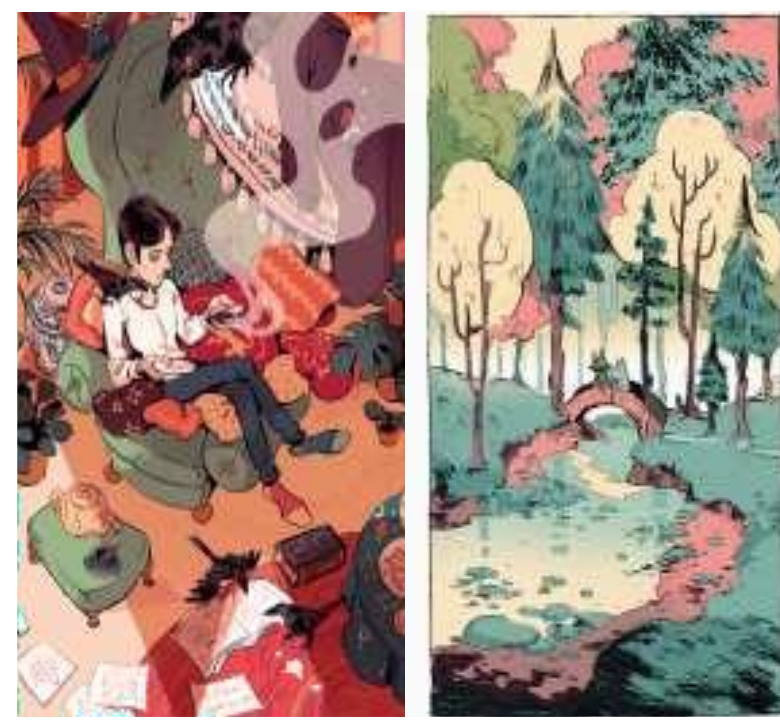

Sumber: https://icamebyunicorn.tumblr.com/

Gambar 1. Contoh ilustrasi dengan kesan warna yang hendak dicapai dalam perancangan

\section{Illustration Visual Style}
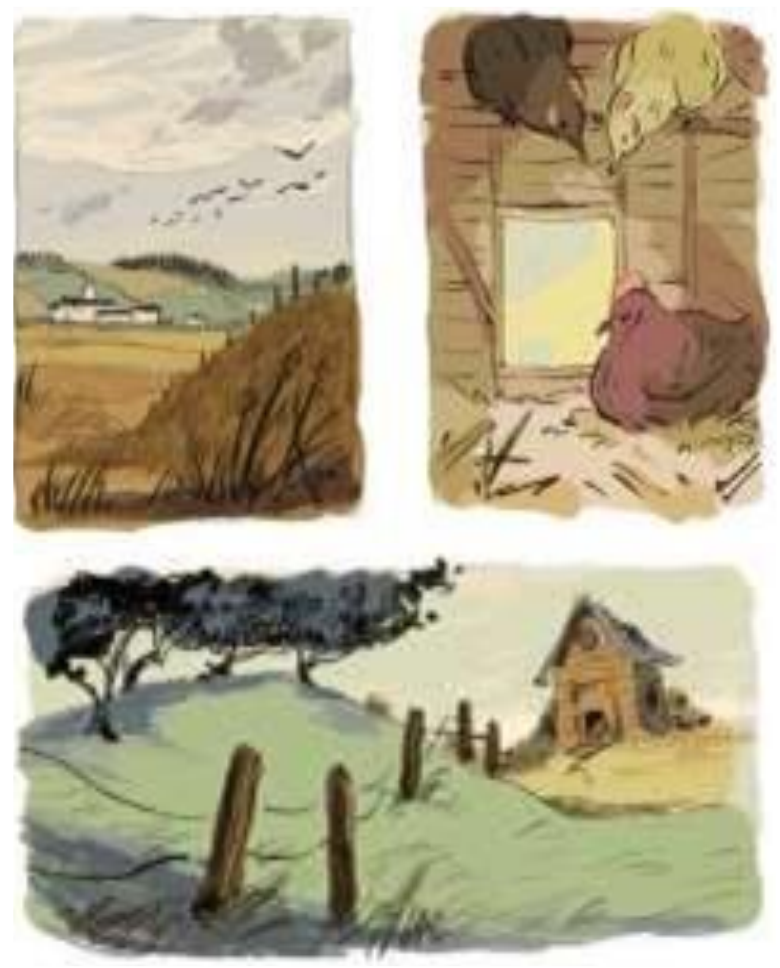

Sumber: https://icamebyunicorn.tumblr.com/

Gambar 2. Contoh gaya sketsa dan pewarnaan yang hendak dicapai dalam perancangan

Ilustrasi akan dikerjakan dengan media digital yang mensimulasikan tekstur media tradisional seperti cat, pensil, dan pen tinta. Gaya ilustrasi yang dijadikan referensi dapat menyampaikan kesan 'kosong, ditinggalkan dan ditelantarkan', terutama pada ilustrasi panoramik. Hal ini untuk mendukung kesan melankolis yang hendak ditimbulkan dengan pemilihan color tone. Kesan inilah yang hendak diemulasikan dalam ilustrasi media. Gaya pewarnaan dan sketsa akan tampak organik baik pada goresan maupun teksturnya.

\section{Gaya Tipografi}

Typeface untuk heading yang akan digunakan dalam media interaktif adalah Averia Serif Libre, yang merupakan typeface serif klasik yang cenderung membulat di ujung-ujungnya. Sementara, bagian body akan menggunakan typeface Montserrat, yang merupakan typeface sans serif untuk memudahkan keterbacaan. Kedua typeface ini mirip dengan typeface yang digunakan dalam koran dan media cetak lain pada tahun 1920-an. Imej dari media-media itulah yang ingin ditimbulkan dari pemilihan typeface ini. 


\section{ABCDEFGHIJK LMNOPQRSTU VWXYZabcdef ghijklmnopqrst uvwXyz}

Gambar 3. Sampel tampilan typeface Averia Serif Libre

\section{ABCDEFGHIJ KLMNOPQRS TUVWXYZabc defghijklmno pqrstuvwxyz}

Gambar 4. Sampel tampilan typeface Montserrat

\section{Proses Perancangan}

Penulisan cerita dilakukan dengan mengambil sudut pandang orang kedua, dan dengan demikian menggunakan kata ganti orang kedua. Sudut pandang ini dipilih dengan tujuan untuk mengajak pemain menempatkan diri dalam posisi tokoh protagonis yang diceritakan di dalamnya. Dengan demikian, berbagai pilihan yang dibuat pemain dalam permainan diharapkan agar didasarkan pada pendapat pribadi pemain dan bukan berdasarkan pilihan mana yang sekiranya paling tepat dalam konteks permainan. Karenanya, deskripsi yang dapat mengidentifikasikan tokoh protagonist sebagai individu yang independen, seperti jenis kelamin, ciri fisik dan sifat dihindari dalam penulisan naskah. Menyesuaikan dengan gaya penulisan ini, tokoh-tokoh lain dalam cerita juga tidak dideskripsikan melebihi yang dibutuhkan untuk mendukung narasi. Hal ini juga untuk menghindari eksposisi yang bertele-tele, karena diharapkan naskah dapat lebih fokus pada informasi terkait subjek yang hendak diangkat.

Menyesuaikan dengan gaya penulisan naskah, ilustrasi pendukung narasi dibuat mengindari penggambaran fisik tokoh-tokoh yang jelas. Hal ini dikarenakan fokus narasi yang lebih pada tokoh pemain dan bukan pada tokoh-tokoh lain di dalamnya. Selain itu, ilustrasi juga diusahakan untuk menggambarkan objek untuk menghindari penggambaran tokoh secara jelas, juga untuk menimbulkan kesan suram.

\section{Sketsa}

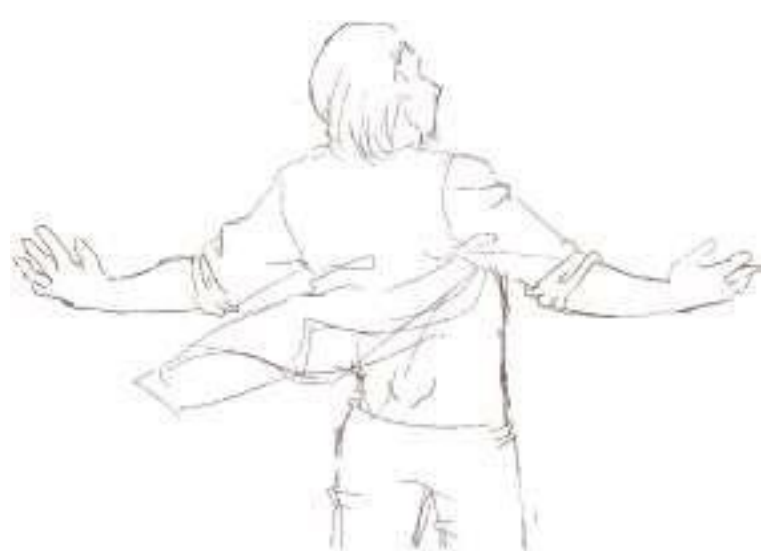

Gambar 5. Contoh sketsa ilustrasi pendukung media pembelajaran

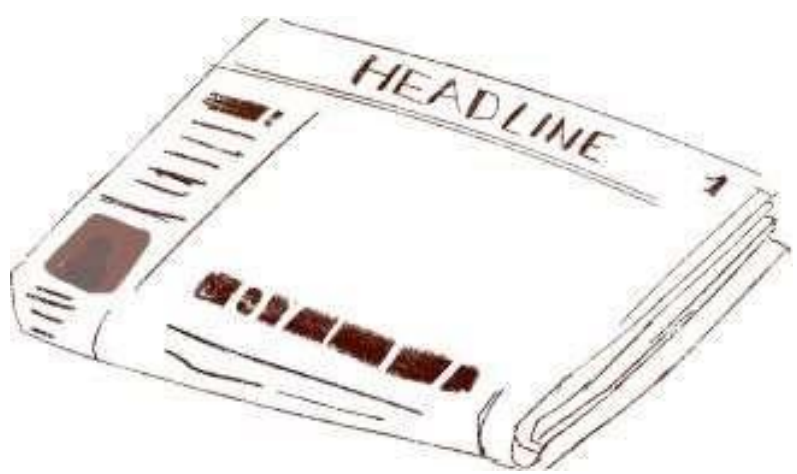

Gambar 6. Contoh sketsa ilustrasi pendukung media pembelajaran

\section{Hasil akhir}

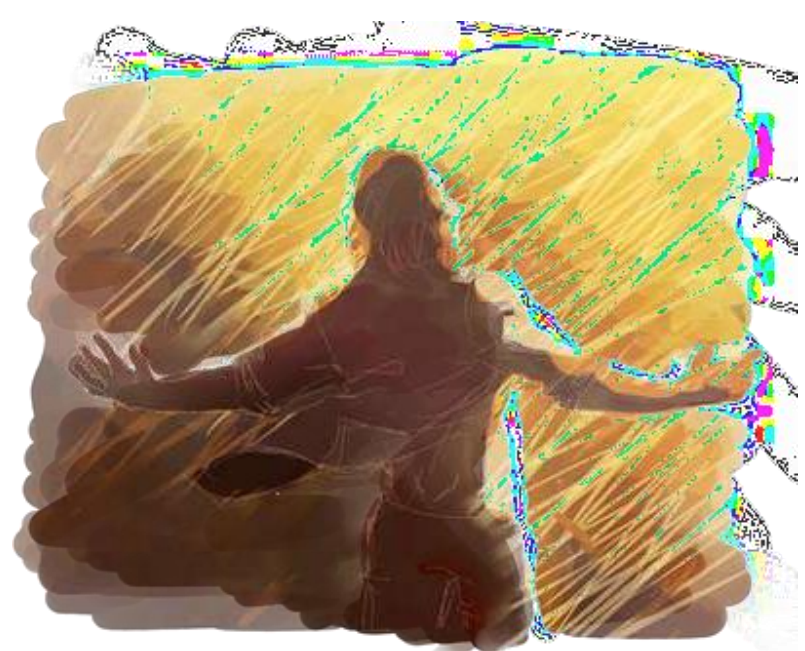

Gambar 7. Contoh hasil akhir ilustrasi pendukung media pembelajaran 


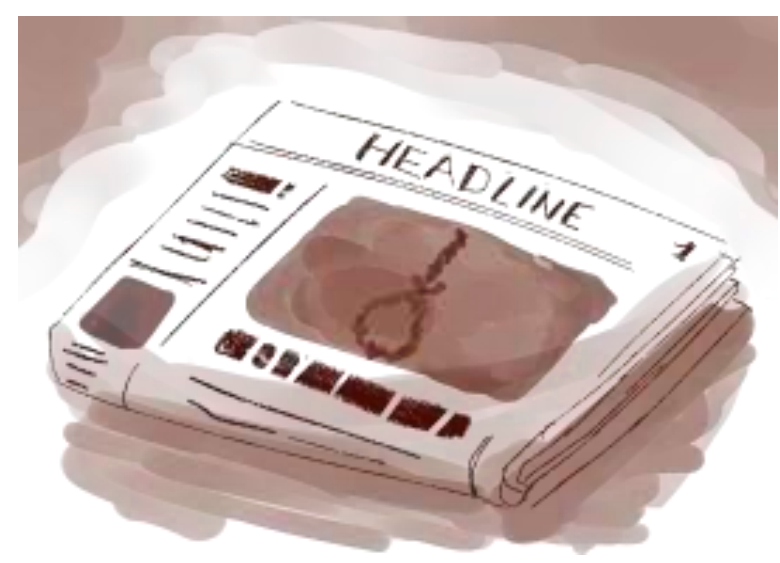

Gambar 8. Contoh hasil akhir ilustrasi pendukung media pembelajaran

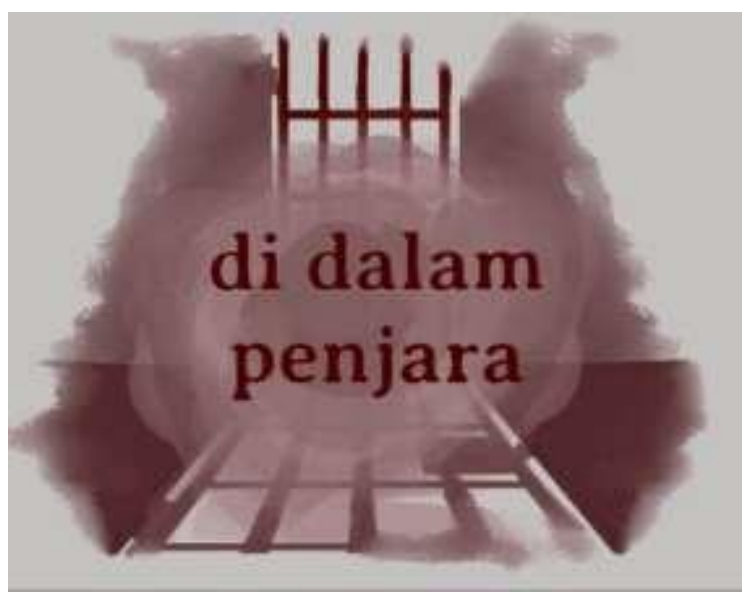

Gambar 9. Ilustrasi yang digunakan dalam title card

\section{Implementasi ilustrasi dalam media}

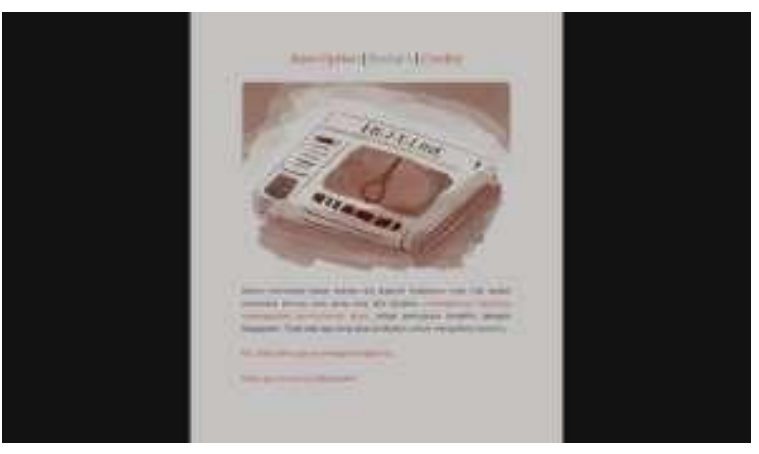

Gambar 10. Contoh implementasi ilustrasi pendukung media pembelajaran

\section{Simpulan}

Hukuman mati merupakan bentuk hukuman terhadap tindak pidana yang kontroversial, dengan diterimanya nilai-nilai hak asasi manusia secara internasional, dan sebagai konsekuensinya terjadi pergeseran tujuan pemidanaan dari yang bersifat retributif dan deterrent menjadi restoratif. Indonesia terutama tertinggal dalam beradaptasi terhadap perubahan nilai dalam masyarakat global tersebut. Indonesia masih memberlakukan hukuman mati sebagai bentuk penghukuman terhadap tindak pidana tertentu dan secara aktif melaksanakan eksekusi dalam sepuluh tahun terakhir. Bertahannya hukuman mati sebagai bentuk penghukuman ini disebabkan sebagian oleh nilai-nilai kultural yang ada di Indonesia yang menghargai penghukuman sebagai bentuk pembalasan untuk mencapai keadilan dan cara untuk memulihkan harga diri.

Hal ini tercermin dalam kebijakan yang diambil oleh pemerintah melalui lembaga pelaksana hukumnya dalam menentukan bentuk hukuman terhadap tindak pidana tertentu, terutama pada tindak pidana yang berkaitan dengan penyalahgunaan narkoba. Dalam situasi yang demikian, masyarakat Indonesia akhirnya menjadi cenderung mendukung pemberlakuan hukuman mati. Dengan kata lain, masyarakat Indonesia cenderung lebih umum melihat perspektif terhadap isu seputar hukuman mati dari perspektif yang pro terhadapnya.

Hasil perancangan ini dibuat dengan harapan dapat memungkinkan target audiens untuk memperoleh pengetahuan tentang hukuman mati, baik dari sudut pandang yang membenarkan maupun mempertanyakan pemberlakuan hokuman mati dalam sistem hukum Indonesia, yang mana diharapkan dapat membuka pandangan target audiens yang bersangkutan terhadap sudut pandang yang berbeda dari yang sebelumnya dipegang olehnya dan memampukannya untuk melihat isu pemberlakuan hukuman mati dengan pemahaman yang lebih lengkap, dan terutama mengedukasikan informasi- informasi berkaitan dengan pandangan yang kontra terhadap hukuman mati.

Sayangnya, berdasarkan hasil tes uji karya pada sejumlah partisipan, secara umum pemain merasakan ketertarikan pada subjek yang diangkat tetapi kurang merasakan engagement dalam pengalaman bermain. Dengan kata lain, karya kurang mampu memberi immersion pada pemain dan memiliki kelemahan sebagai sebuah bentuk hiburan (entertainment).

Penulis menyadari bahwa permainan Interactive Fiction ini masih belum sempurna dan mempunyai banyak kekurangan, baik dalam hal narasi, engagement, dan visualisasi. Untuk dapat mencapai hasil yang lebih maksimal dalam pengerjaan proyek serupa, diperlukan penjadwalan dalam proses pengerjaan dan fokus terhadap proyek yang bersangkutan, serta pendalaman pengetahuan mengenai teknis pemrograman menggunakan alat yang terkait, yang mana penulis sadari merupakan hal-hal yang berkekurangan dalam proses pengerjaan yang penulis lakukan. 


\section{Daftar Pustaka}

Amnesty International. (2019). Death Penalty. Retrieved from https://www.amnesty.org/en/ what-we- do/death-penalty/

Amnesty International. (2018) Abolitionist and retentionist countries as of July 2018. Retrieved March 18, 2020from https://www.amnesty. org/download/Documents/ACT 5066652017ENGLISH.pdf

Bayuni, Endy. (2015, January 23). Commentary: capital punishment and public opinion. Retrieved from https://www.thejakartapost. com/ news/2015/01/23/commentary-capitalpunishment-and-public-opinion.html

Dessoff, Alan. (2010). Reaching Digital Natives on Their Terms. District Administration.

Deterding, Sebastian, Dixon, Dan, Khaled, Rilla \& Nacke, Lennart. (2011). From Game Design Elements to Gamefulness: Defining Gamification. Proceedings of the 15th International Academic MindTrek Conference: Envisioning Future Media Environments, MindTrek 2011. 11. 9-15. 10.1145/2181037.2181040.

Djaouti, Damien, Alvarez, Julian, Jessel, JeanPierre. (2011). Classifying Serious Games: the G/P/S model. France: University of Toulouse.

Hayati, Titin, Radiana, Usman, Sulistyarini. (2014). Pengembangan Media Pembelajaran berbasis Weblog dalam Pembelajaran Pendidikan Kewarganegaraan untuk Kecakapan Belajar Kelas X. Retrieved from http://jurnal. untan.ac.id/index.php/jpdpb/article/view/4568.

Hood, R. (2019, December 26). Capital punishment. Encyclopædia Britannica. Retrieved March 16, 2020 from https://www.britannica.com/topic/ amnesty.

Johnson, David T. (2010). Asia's Declining Death Penalty. The Journal of Asian Studies, 69, 337346

Katadata. (2018, February 23). Usia Produktif Mendominasi Pengguna Internet. Retrieved from https://databoks.katadata.co.id/datapublish/2018/02/23/usia-produktif-mendominasipengguna- internet/

Katsaounidou, Anastasia, Vrysis, Lazaros, Kotsakis, Rigas, Dimoulas, Charalampos, \& Veglis, Andreas. (2019) MAthE the Game: A Serious Game for Education and Training in News Verification. Retrieved from https://www. mdpi.com/2227- 7102/9/2/155/htm

Kronenwetter, Michael (2001). Capital Punishment: A Reference Handbook (2 ed.). Retrieved from https://books.google.co.id/books?id=SO iuzOv061EC\&lpg=PP1\&dq=isbn\%3A9781576 074329\&pg=PA1\# v=onepage\&q\&f=false
Lancy, David F., Hayes, Bernard L. (1988). Interactive Fiction and the Reluctant Reader. The English Journal. 77(7), 42-46.

Lubis, Todung Mulya. (2015). Death Penalty and the Road Ahead: A Case Study of Indonesia (CILIS report no. 9, ALS report no. 4). Retrieved from Asian Law Centre-Centre for Indonesian Law, Islam and Society website.

Martin, Algonso G., Tyner, Kathleen. (2012). Media Education, Media Literacy and Digital Competence. Comunicar Journal 38: Media Literacy in Multiple Contexts, 19(3), 31-39.

McGuire, Eric. (2015, April 6). How Harry Gleeson was wrongly hanged for murder in 1941. Retrieved fromhttps://www.irishtimes.com/ news/crime-and- law/how-harry-gleeson-waswrongly-hanged-for-murder-in-1941-1.2165731

McRae, Dave (2012) A Key Domino? Indonesia's Death Penalty Politics. Sydney: Lowey Institute for International Policy.

Montfort, Nick. (2005). Twisty Little Passages: An Approach to Interactive Fiction. Massachusetts: MIT Press.

Mulyadi, Mahmud (2010). Perlindungan Terhadap Anak Yang Berkonflik Dengan Hukum: Upaya Menggeser Keadilan Retributif Menuju Keadilan Restoratif. Medan: University of Sumatera Utara Institutional Repository.

Novak, Andrew. (2013). The Future of the Mandatory Death Penalty in Malaysia and Singapore: "Asian Values" and Abolition in Comparative Perspective with Implications for Indonesia. Indonesia: Institute for Migrant Rights https:/law.unimelb.edu.au/centres/cilis/resear ch/publications/cilis-policy-papers/deathpenalty-and-the- road-ahead-a-case-study-ofindonesia

Oxford Analytica. (2019). Concern over death penalty will grow in Asia-Pacific. Retrieved March 19, 2020 from https://www.emerald. com/insight/content/doi/10.1108/OXAN-GA24 6791/full/html

Ryan, Marie-Laure. (2009). From Narrative Games to Playable Stories: Toward a Poetics of Interactive Narrative. Storyworlds: A Journal of Narrative Studies. 1(3), 43-59.

Suara Pembaruan. (2015). Bergeming pada Eksekusi Mati. Retrieved from http://sp.beritasatu. com

Van Ness, Daniel W., Karen Heetderks Strong. (2010). Restoring Justice - An Introduction to Restorative Justice. 4th ed. New Province, N.J.: Matthew Bender \& Co., Inc.

Video game. (2019). In Merriam-Webster.com. Retrieved May 27, 2019, from https://www. merriam-webster.com/dictionary/video $\% 20$ game. 